\title{
Contactless measurement of cow behavior in a milking robot
}

\author{
M. PASTELL, A.-M. AISLA, and M. HAUTALA \\ University of Helsinki, Helsinki, Finland \\ V. POIKALAINEN, J. PRAKS, and I. VEERMÄE \\ Estonian University of Life Sciences, Tartu, Estonia \\ and \\ J. AHOKAS \\ University of Helsinki, Helsinki, Finland
}

\begin{abstract}
We have worked on automatically measuring the behavior of dairy cows during automatic milking. A milking robot offers a unique possibility for a dynamic measurement of physical data. Four strain gauge scales were installed into a milking robot in order to measure the weight of each leg separately, and a laser distance sensor was placed next to the robot in order to measure the radial movement of the cow's body surface. The data were collected into a PC. Three video cameras were installed to observe the system, and the data were recorded digitally. From the data, the dynamic weight or load of each leg and the respiration rate of a cow could be measured. Different stages of milking were observed, and the changes in behavior during milking were analyzed. The acquired information could be used to judge a cow's restlessness and welfare-for example, leg health and stress.
\end{abstract}

The step and kick behavior of a cow can be used when animal welfare is studied. Rousing, Bonde, Badsberg, and Sørensen (2004) found that a higher kick frequency during milking may be the result of pain or discomfort caused by, for example, teat lesions. However, they did not find any relation between lameness and increased stepping or kicking during milking. They suggested that behavioral measurements during milking might be a good tool for monitoring welfare problems, such as udder health, milking techniques, and the quality of handling routines in individual herds. According to Wenzel, Schönreiter-Fischer, and Unshelm (2003), increased step frequency during milking correlates with an increased heart rate and milk cortisol concentration.

An increased respiration rate in dairy cows has been associated with an increased dry bulb temperature (Eigenberg, Brown-Brandl, Nienaber, \& Hahn, 2005) and an increase in solar radiation (Spain \& Spiers, 1996). It has been proven to be a good indicator of heat stress (Brouk, Smith, \& Harner, 2003; Spiers, Spain, Leonard, \& Lucy, 2001). Spiers et al. also found a positive correlation between increased rectal temperature and respiration rate. Automatic monitoring of respiration rate enables quick detection of the symptoms of heat stress and provides

The authors acknowledge the Finnish Ministry of Agriculture for financing the KARTEK project and the Estonian Science Foundation for Grants 5741, 5742, and 6053. Correspondence concerning this article should be addressed to M. Pastell, Department of Agrotechnology, University of Helsinki, P.O. Box 28, FI-00014 Helsinki, Finland (e-mail: matti.pastell@helsinki.fi). a means for assessing the severity of a stress condition. This can reduce performance losses and even prevent the death of animals (Brown-Brandl et al., 2005; Eigenberg et al., 2005; Eigenberg, Nienaber, \& Brown-Brandl, 2003; Mader, Dahlquist, Hahn, \& Gaughan, 1999). Monitoring of respiration can also provide valuable information about other diseases, stress factors, and the welfare of a cow.

Howell and Paice (1989) developed an adaptive datalogging system for animal power studies. They were able to record the respiration rate of a working ox with a clip attached to the animal's nose. The system, however, needed an operator to walk next to the animal with a portable computer during the measurement. Eigenberg, Hahn, Nienaber, Brown-Brandl, and Spiers (2000) have developed a system for monitoring the respiration rate, but it has to be put on the animal with a special belt. In addition, the system does not have the possibility for real-time monitoring, because the data are saved in a datalogger. Others have measured the respiration rate with a stopwatch, visually observing the movement of the cow's body surface (Brouk et al., 2003; Spiers et al., 2001).

We have developed a system for measuring the leg weights of dairy cows during automatic milking without disturbing the cow. The system was initially set up to monitor changes in the leg loads in order to find hoof problems (Pastell et al., in press), but also kicking and stepping behavior can be calculated from the results. This behavior is connected with hoof problems and, also, with milking problems. From the data, the average weight, the weight variation of each leg, the total weight, and the number and frequency of kicks and steps can be calculated. Now, we 
have added laser-based respiration-rate-measuring equipment to the system in order to monitor changes in respiration rate.

It is likely that by continuously monitoring behavioral changes, we can obtain valuable information about the stress level and health of animals. The information about a cow's behavior during different stages of milking could be used, for instance, for lameness detection or for designing milking systems and setting up correct vacuum levels for the milking machine. The aim of this article is to introduce new techniques and tools for behavior research and health monitoring of dairy cows. The article focuses mainly on the technical aspects of the system and presents some preliminary results from automatic contactless monitoring of respiration rate and step-kick behavior.

\section{MATERIALS AND METHOD}

\section{Measurements}

A system for automatic measurement of the leg weights and respiration rates of dairy cows in a milking robot was developed. The system consists of four balances, a laser distance sensor, wiring, a carrier frequency amplifier, and a computer for collecting the data. Figure 1 shows the components of the measurement system.

The measurements were conducted in a DeLaval VMS milking robot at the research farm of the University of Helsinki. DeLaval VMS is a single-stall milking robot, with one robot handling each individual stall. In a multistall system, single robots have the capacity to handle up to four stalls, resulting in higher capacity (de Koning, van der Horst, \& Meijering, 2002). At the research farm, the cows are milked, on an average, three times a day, and one robot milks 40-50 Holstein cows. In an automatic milking system, cows are milked in a milking box without human contact. A milking robot is planned to manage every stage of milking without a cattle tender.

The balances are located in the floor of the milking robot under a rubber carpet. Each balance is constructed from a plywood plate on top of a steel plate that is attached to a strain gauge (Vishay Tedea-Huntleigh 1510) with a capacity of $500 \mathrm{~kg}$. The size of the balances ranges from $310 \times 310 \mathrm{~mm}$ to $390 \times 445 \mathrm{~mm}$, depending on the location and the robot's chassis structures (Figure 2). The plates that are located under the hind legs are a bit larger than the plates under the front legs, because it was discovered that the position of the hind legs of different cows during milking varies more than does the position of front legs. The balances were carefully calibrated after installation, and the calibration was checked twice during the measurement period of 5 months. It was found out that the calibration of the balances did not change over time and did not, therefore, account for error in the measurements. Figure 2 shows the installation of strain gauges in the floor of the robot and the location of the plates on top of the four balances as they are positioned in the robot.

The laser distance sensor (L-Gage LT3, Banner) was placed next to the robot, pointing at the left side of regio abdominis lateralis of a cow from under the robot's chassis (Figure 1). The correct position for the sensor was found by measuring the respiration rate from different locations on the cow's side and visually comparing the movement of the body surface with the measured signal. Visual comparison was possible because the respiration frequency is relatively slow-typically, from 0.3 to $0.7 \mathrm{~Hz}$. It was found that the correct frequency could be measured from quite a large area on the cow's side and that the same sensor location could be used for most of the cows, even though the laser beam did not hit all the cows at the same spot. The only limitation was that the laser could not be used for black cows, because the black hair absorbed the laser. However, the black and white Holstein cows at the research farm typically had white hair in the measurement area, so it was not a problem in this study.

The computer and the carrier frequency amplifier (Spider8, HBM) were located in the office of the cowshed, so 40-m-long wiring was needed. The balances were also automatically tared during the automatic maintenance of

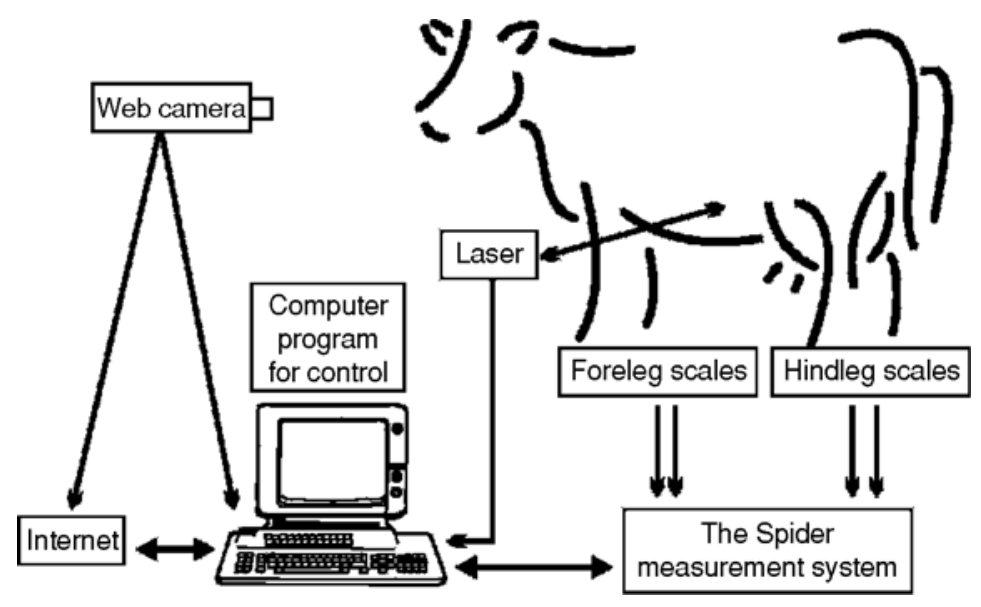

Figure 1. The components of the measurement system. 


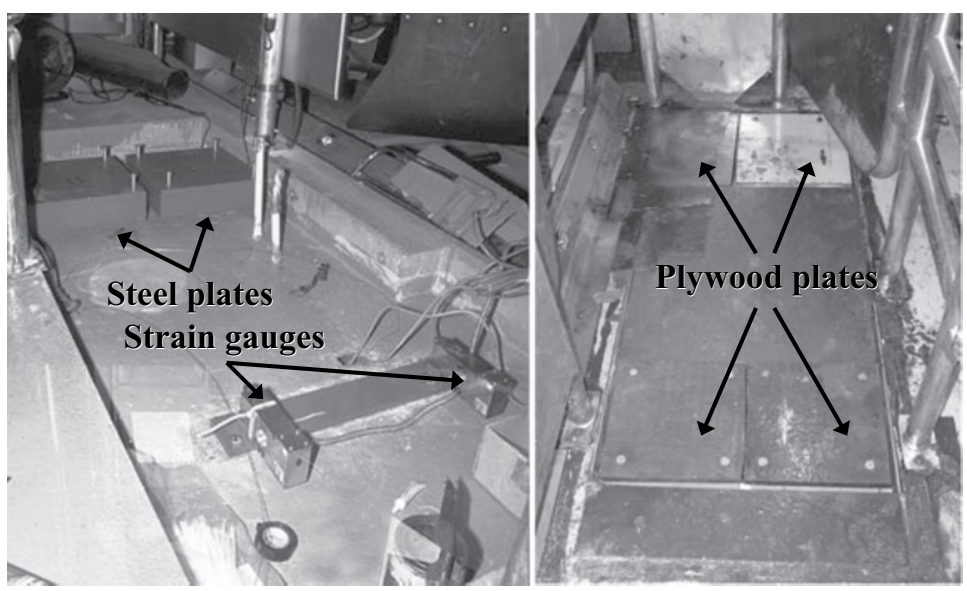

Figure 2. The strain gauges on the floor of the milking robot and the plywood plates on top of the balances as they are positioned on the floor of the milking robot.

the robot, which took place at least three times a day. Despite the long wires, the system worked with a low noise level, but some drifting still occurred as a function of temperature.

The measurements were controlled by a dedicated computer program made with Labview 7.1 (National Instruments). The software controlled the measurements based on the cow ID and the robot's actions. This information was obtained from a log file created by software provided by DeLaval. The software started to record the leg weights and the respiration rate of a cow when the milking started and saved the recorded data on the hard disk when the milking ended. The measurement rate was set to $100 \mathrm{~Hz}$, which is the maximum sample rate with the current installation, in order to see the changes in respiration rate with the highest possible resolution. After the measurement had ended, the software automatically calculated the mean weight and the standard deviation of the weight of each leg and the number of kicks during milking for each cow. The data from the laser sensor was saved on the computer, and it was analyzed later with Labview 7.1.

The cow's behavior during milking was recorded with a Web camera. The behavioral actions of the cows were studied from the video files in connection with different stages of milking. These stages were (1) washing the teats, (2) attaching teat cups, (3) milking, and (4) removing the teat cups. Kick offs and any unusual behavior were also recorded. A remote connection via the Internet was used for downloading the data, as well as tracking of the measurements together with the real-time video.

\section{Data Analysis}

Weight data. Leg weights from over 13,000 milkings and 72 cows were recorded during 5 months. The recorded data were downloaded from the measurement computer, and MATLAB 7.0.4 was used for analyzing the data. The data were automatically corrected from erroneous values with a special algorithm (Pastell et al., in press). After the data had been corrected, the number of kicks and steps during each milking was calculated.

A kick was defined as a cow's lifting a leg up, and one kick was calculated when the leg weight of a cow decreased to below $5 \mathrm{~kg}$ (the drifting sometimes moved the zero level to $5 \mathrm{~kg}$ ). A step was defined as weight shuffling, and a step was calculated from the data when the weight of a leg decreased to between 5 and $20 \mathrm{~kg}$.

A $t$ test for two independent samples was conducted to find out whether there was a statistically significant difference in the step and kick behavior of the multiparous and the primiparous cows during milking. Also, the leg health of the cows was inspected regularly during this study, and the effect of lameness on the cow's behavior was looked into.

The sum of steps and kicks of the hind legs was calculated for those 20 cows that had a problem in one or both hind legs. The cows were observed during milking in the lame (813 measurements) and the healthy (3,101 measurements) periods, and the change in step and kick behavior was observed. A Mann-Whitney $U$ test was used to compare the data of each cow from healthy and lame periods, to test whether there was a statistically significant difference in the behavior between the two periods.

Respiration rate. The laser sensor gives information only about the radial movement of the body surface (RMBS). In addition, the signal also contained some amount of high-frequency noise caused by the fluorescent lamps in the cowshed. Before analyzing the frequency of respiration, the noise had to be filtered from the data. Several IIR and FIR filters were used to experiment with the data in order to find the appropriate filter. The secondorder Butterworth band-pass filter with passband between 0.1 and $3 \mathrm{~Hz}$ was selected and applied to the respiratory data. After the data had been filtered, the frequency was then extracted from the data with 1,024-point fast Fou- 

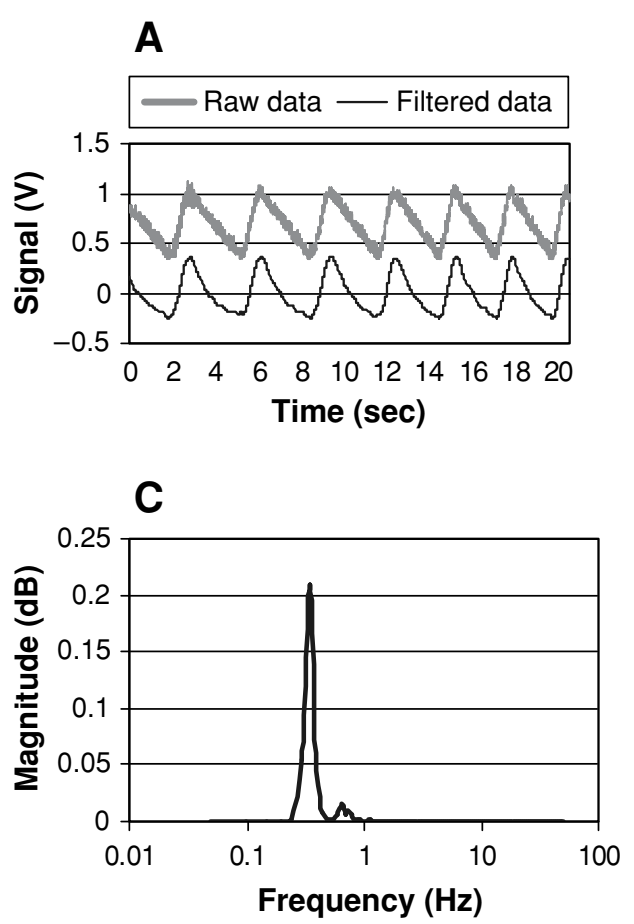

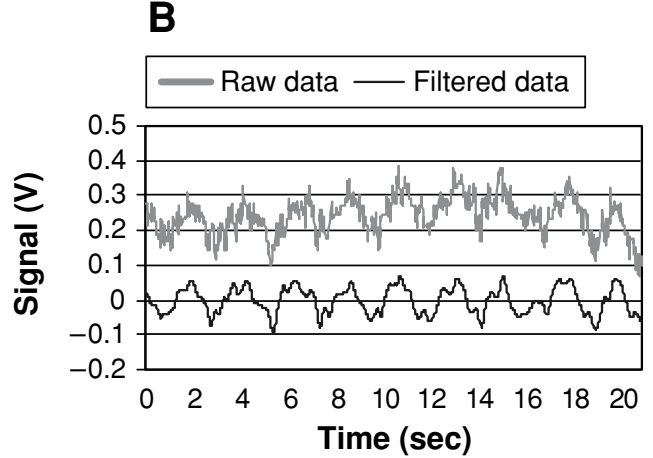

D

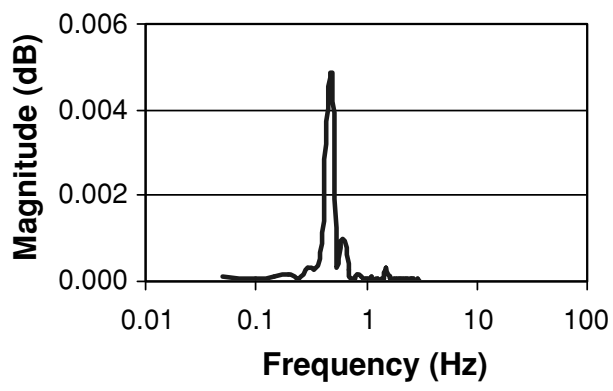

Figure 3. (A) Raw data and filtered data from the laser sensor with 3-m wiring. (B) Raw data and filtered data from the laser sensor with 40-m wiring. (C) Power spectrum from the data measured with 3-m wiring. (D) Power spectrum from the measured data with 40-m wiring.

rier transform (FFT). With the used measurement rate $(100 \mathrm{~Hz})$, the resolution of the calculated respiration rate was 6 breaths $/ \min (=0.1 \mathrm{~Hz})$.

The measurements were first made with a temporary installation with 3-m wire from the sensor to the data acquisition unit, but in the final installation, 40-m-long wiring was needed, in order to connect the sensor to the amplifier and the computer. The long wiring introduces additional noise to the signal, which cannot be completely filtered. However, the respiration rate can be figured out from the data of both installations.

Figure 3 shows the raw and filtered data from the laser signal with the 3- and 40-m wiring. The RMBS acquired with $3-\mathrm{m}$ wiring shows that the phase of inspiration is shorter, in comparison with the phase of expiration (Figure $3 \mathrm{~A}$ ). From the data acquired with $40-\mathrm{m}$ wiring, this information is lost, but the movement can still be seen from the signal (Figure 3B). The frequency can be calculated with FFT $(n \mathrm{FFT}=1,024)$ from the signals measured with the $3-\mathrm{m}$ (Figure 3C) and 40-m (Figure 3B) wirings.

\section{RESULTS}

Figure 4 shows the mean number of kicks and steps during 1 month for multiparous and primiparous cows. The average number of kicks for multiparous cows was 9.9 times/milking, and for primiparous cows it was 4.5 . The average number of steps for multiparous cows was 25.9 times/milking, and for primiparous cows it was 14.6. The figure also shows that the deviation in the number of steps and kicks was a lot higher for multiparous cows. Also, a $t$ test gave a statistically significant difference $(p<.01)$ between the mean number of steps and kicks of multiparous and primiparous cows.

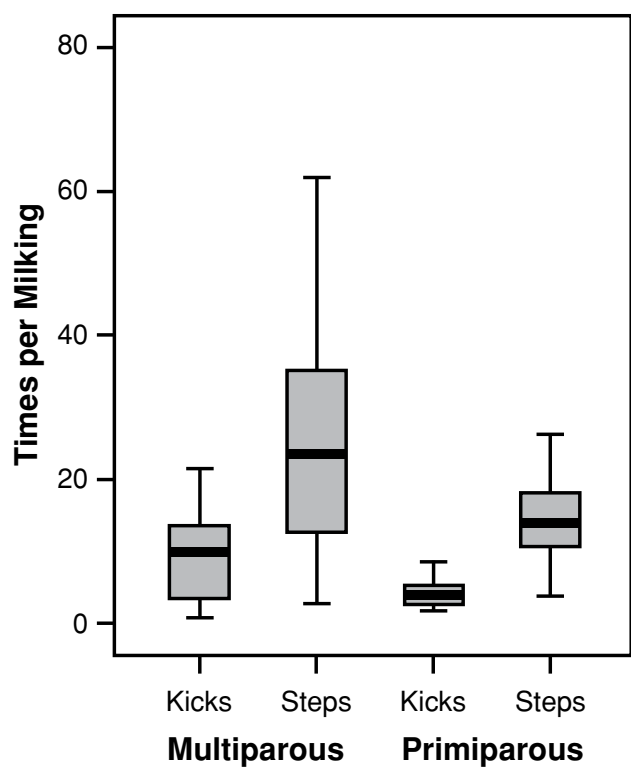

Figure 4. The mean number of kicks and steps during milking in August 2004 for multiparous $(n=28)$ and primiparous $(n=$ 21) cows. Center line, median; box, quartiles; whiskers, extreme values. 


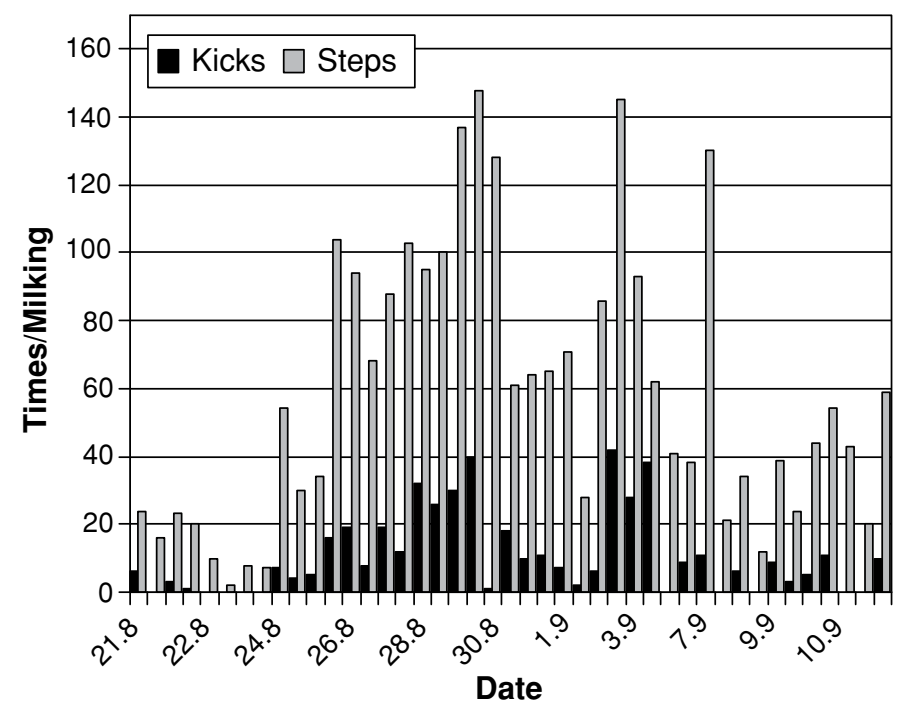

Figure 5. The number of kicks and steps of 1 cow during milking between August 21 and September 10.

Figure 5 shows the number of kicks and steps of a cow that had injured a leg during the experimental period. The cow injured her leg on August 25, and that can be seen in the data as a significant increase in stepping and kicking frequency. The high number of steps was caused by the cow's constantly lifting the injured leg. The injury healed by itself, and the step and kick behavior of the cow returned to normal.

The sum of kicks and steps with the hind legs during milking for those 20 cows that became lame during the observation period is given in Figure 6. For some cows, a clear increase in the amount of movement during the period of lameness can be seen from the data. However, not all of the cows showed the same behavior, and sometimes, no clear difference in behavior was observed during lame and healthy periods. This explains why Rousing et al. (2004) did not find any correlation between number of kicks and lameness. The data from healthy and lame periods for each cow were compared using a Mann-Whitney $U$ test. It showed a statistically significant $(p<.05)$ difference between the two periods for $85 \%$ of the cows. The average number of the sum of kicks and steps with the

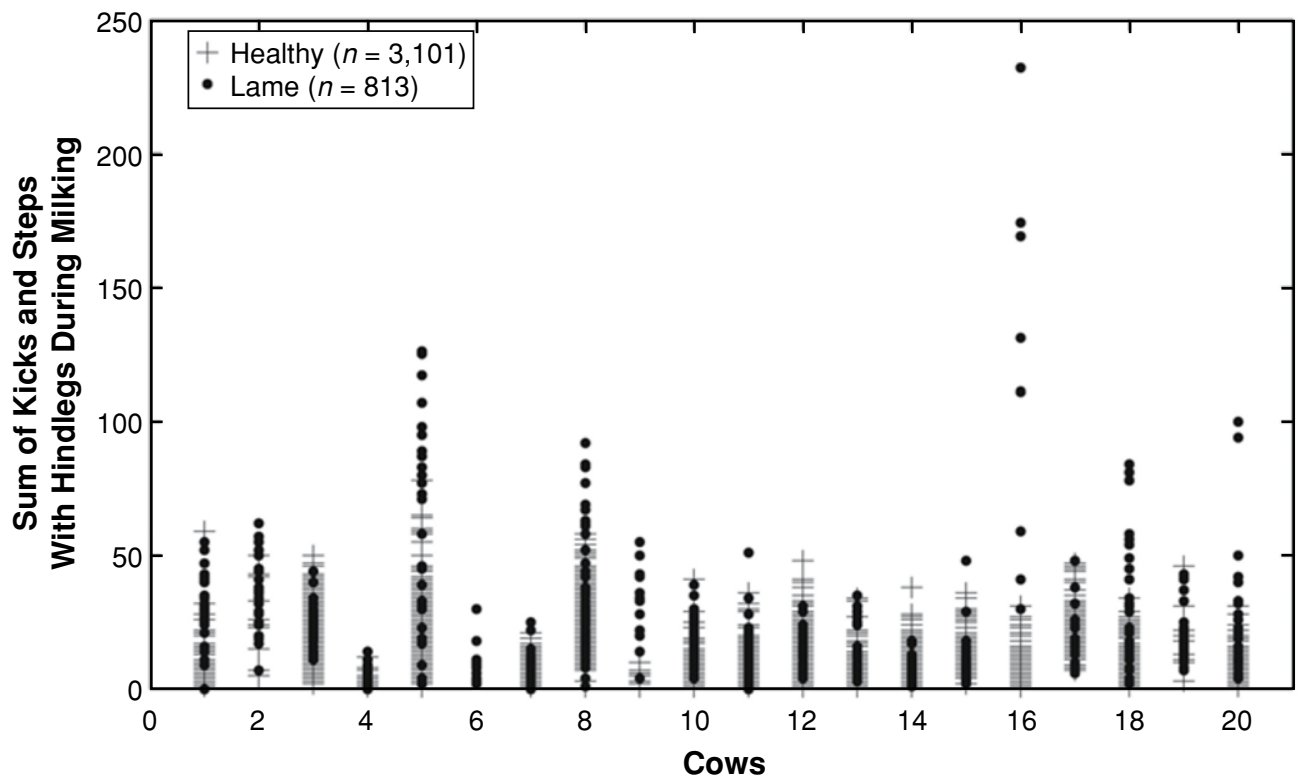

Figure 6. The sum of kicks and steps with the hind legs during milking for 20 cows during healthy and lame periods. 
hind legs for the lame period was 17.5 times/milking, with a standard deviation of 20.6, and for the healthy period, the average number was 13.2 times/milking, with a standard deviation of 10.7 .

It is also possible that mastitis can be seen from the step and kick behavior of a cow during milking. Figures 7 and 8 show the weight of the hind legs of a cow with mastitis and a healthy cow during milking. The cow with mastitis was restless during the whole milking, and the kick frequency was very high, whereas the healthy cow stood evenly, and the kick frequency was low. The kicks can be seen from the data as sharp drops and rises in the weight of the kicking leg.

Figure 9 shows the weight of the hind legs of a cow during one milking. Kicks and steps can be figured out as peaks from the data. The figure shows that the cow was quite calm during the teat cleaning and teat cup attachment. She became restless at the end of the milking stage, when the milk flow decreased from at least one of the quarters before the teat cup was automatically disconnected. Restless behavior occurred also at the end of the

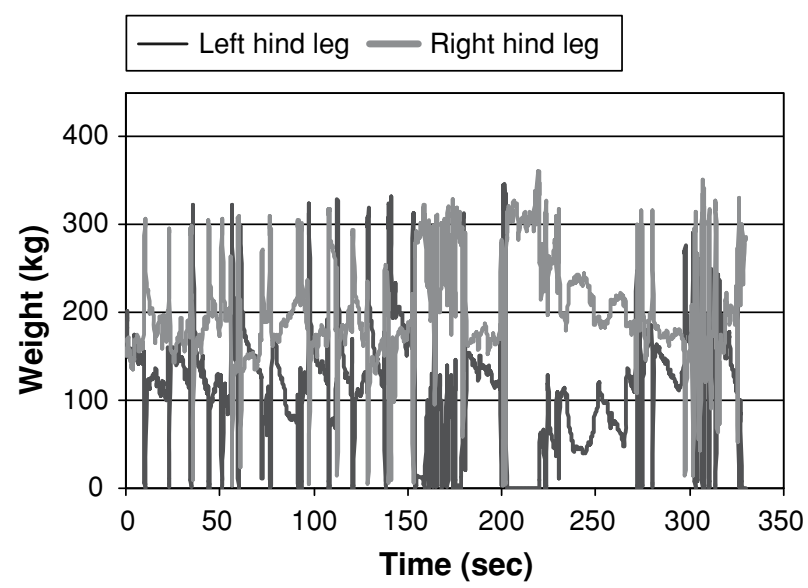

Figure 7. The weight of the hind legs of a cow with mastitis during milking.

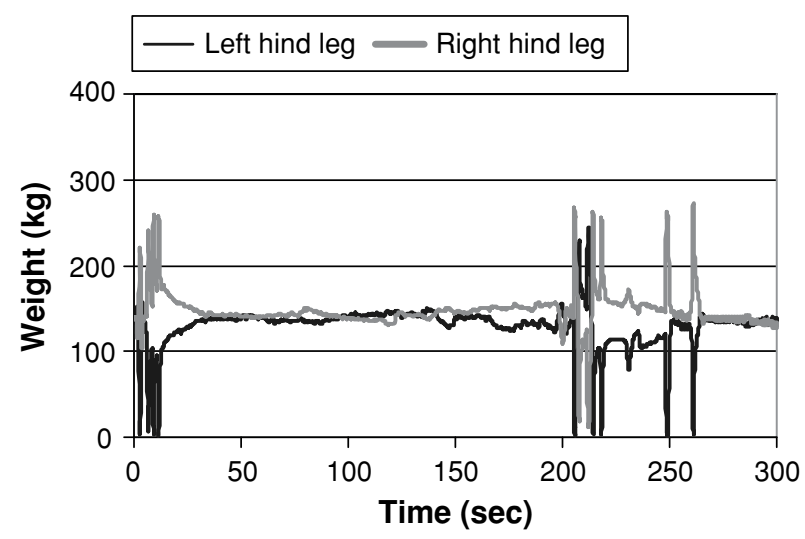

Figure 8. The weight of the hind legs of a healthy cow during milking. removing stage, when the milk flow from the still-attached quarters decreased.

The change in the respiration rate of a cow during one milking is shown in Figure 10. The respiration rate is obtained with FFT $(n$ FFT $=1,024)$ from a filtered laser signal. The respiration rate was fairly constant throughout the milking. It rose only momentarily when the cow was moving sideways and then decreased for $40 \mathrm{sec}$ after the movement. The movement of the cow can also be seen as peaks in the filtered data.

\section{DISCUSSION}

This system can be used for contactless real-time monitoring of the respiration rate and the step and kick behavior of dairy cows. Measurements have been fully automated, and algorithms for counting the number of kicks and steps have been developed. However, the balances are constantly subject to severe loads, and the fixing of the transducers and platforms has raised problems due to the loading of the leg, since the transducers were not designed for concentrated point loads but for larger load area. The analysis of respiratory data was made offline, but online analysis software will be developed in the near future.

The laser sensor has proven to be a reliable method for measuring the respiration rate of dairy cows. Long wiring in the installation causes noise to the signal, but it can be filtered from the data, and the changes in the respiration rate can be extracted from the data. The filtered respiratory pattern of a cow has a great resemblance to that recorded from humans (Brink, Mueller, \& Schierz, 2006). With shorter wiring, even the difference in the speed of inhaling and exhaling can be seen from the data. This information, along with the respiration rate, can give information about the stress and health status of a cow. Resolution of the calculated respiration frequency is currently limited to 6 breaths/min $(0.1 \mathrm{~Hz})$, because of the $100-\mathrm{Hz}$ measurement rate and the number of points included in FFT $(1,024)$. The resolution could be improved by increasing the number of points used in FFT and, consequently, increasing the time window, but this would decrease the system's ability to measure changes over time. The advantage of the laser sensor is that it can be used for daily monitoring of multiple animals with a single sensor. This offers the possibility of creating an automatic alarm system - for example, for heat stress. Moreover, there is no need to attach anything on the animal, as opposed to using a respiratory belt (Brouk et al., 2003; Spiers et al., 2001) or a clip (Howell \& Paice, 1989). The laser will be connected to a wireless data logger in the future in order to eliminate noise from extensive wiring.

A calm cow can be separated from a restless one, and changes in the behavior of individual cows can be monitored. The multiparous cows had higher step and kick frequency during robotic milking than did primiparous cows, and there was also more variation in the step and kick behavior of multiparous cows.

The system has also shown promise for lameness detection, since clear lameness cases often result in a very high 


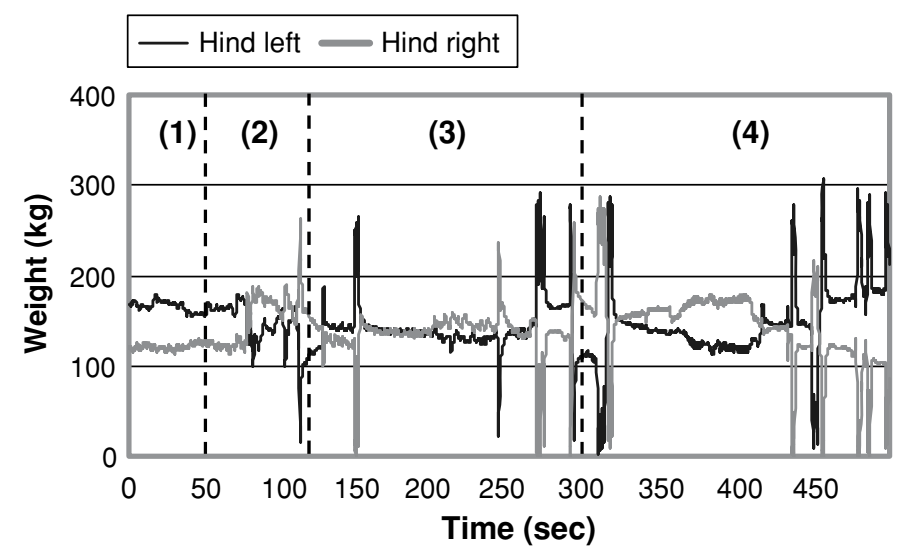

Figure 9. The weight of the hind legs of a cow during different stages of milking. 1 , washing the teats; 2 , attaching teat cups; 3 , milking; 4 , removing teat cups (kick, below $5 \mathrm{~kg}$; step, peak from 5 to $20 \mathrm{~kg}$ ).

stepping frequency when the cows try to relieve the pain on the affected leg. This information, together with the leg load distribution, will be used to develop a predictive model for lameness detection that will be validated with future measurements. It might also be possible to use the system for mastitis detection.

Social isolation from other cows in unfamiliar surroundings has been found to increase the behavioral aspects of acute stress (Rushen, Boissy, Terlouw, \& de Pasillé, 1999). In the automatic milking system, a cow is isolated from a herd during milking, but visual contact with other cows remains. This raises the question of whether the automatic milking stall is so isolated that it presents stress factors for a cow. Another interesting factor is the effect of human contact. Some indicators of acute stress-for example, defecation - have decreased significantly when positive contact with a cattle tender occurs in unfamiliar surround- ings (Boissy \& Le Neindre, 1997). Respiration rate and step/kick behavior could be used for monitoring the stress level and discomfort of cows between automatic and conventional milking systems.

It could be possible to find out the best vacuum level and the best liner types for a herd by monitoring cow behavior during different stages of milking. The stage of disconnecting teat cups could be set by using information about cow behavior. Overmilking is unpleasant for a cow, and it could be one reason for restless behavior during teat cup removal. In this study, the restlessness of the observed cows greatly increased toward the end of milking, suggesting that the animals were experiencing discomfort. In an automatic milking system, there is no cattle tender performing visual evaluation of teat condition after milking, as in conventional milking systems, and automatic means for monitoring cow comfort are needed.

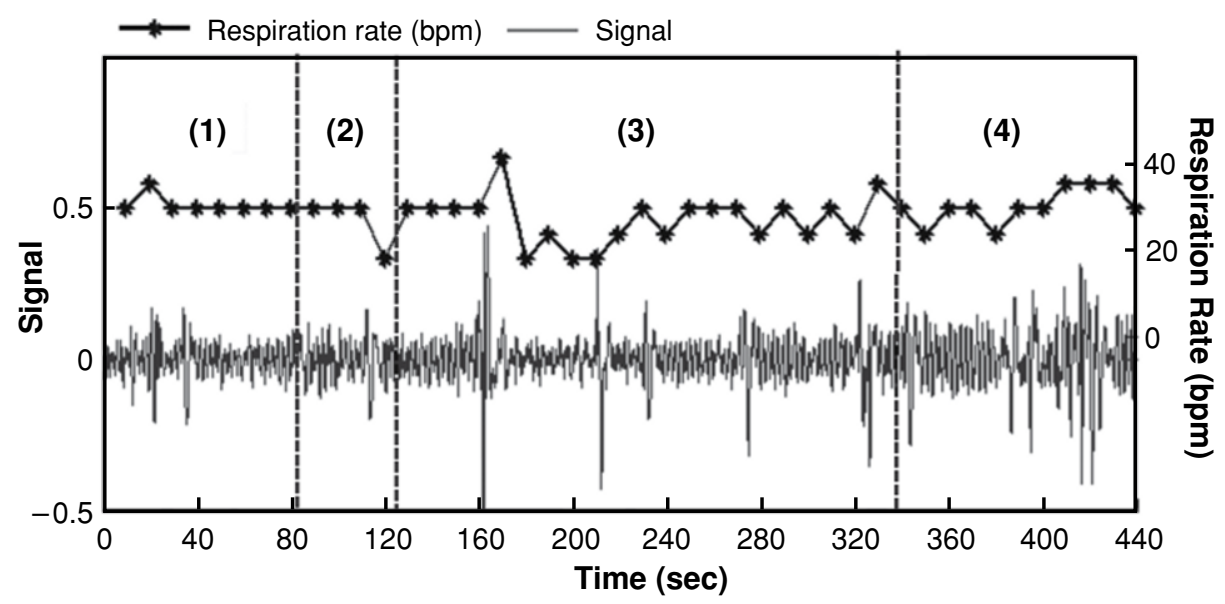

Figure 10. Filtered respiration signal and the changes in respiration rate (resolution $=6$ breaths/ min) during different stages of milking. 1 , washing the teats; 2 , attaching teat cups; 3 , milking; 4 , removing teat cups. 


\section{CONCLUSIONS}

A laser distance measurement system can be used for automatic registration of the respiratory data of cows. For sophisticated elaboration of these data, a special computer program is needed. The distribution of leg weights and their dynamics in time can provide a basis for the detection of leg disorders. To a certain extent, the cow's behavior influences the leg load distribution. An automatic system based on leg weights can be used to monitor the health status of animals.

The behavior of a cow can be seen from the data; that is, a calm cow can be separated from a restless one. The number of kicks can be calculated from curves, and a quantitative measure of restlessness can be figured out.

In the future, the milking robots or feeding automates can be equipped with an automatic weight and respiration rate measurement system and with an alarm system to announce changes in the behavior of a cow.

\section{REFERENCES}

BoIssy, A., \& LE NeINDRE, P. (1997). Behavioral, cardiac and cortisol responses to brief peer separation and reunion in cattle. Physiology \& Behavior, 61, 693-699.

BrinK, M., Müller, C. H., \& Schierz, C. (2006). Contact-free measurement of heart rate, respiration rate, and body movements during sleep. Behavior Research Methods, 38.

Brouk, M. J., SMith, J. F., \& Harner, J. P. (2003). Effect of sprinkling frequency and airflow on respiration rate, body surface temperature and body temperature of heat stressed dairy cattle. In K. Janni (Ed.), Proceedings of the Fifth International Dairy Housing Conference (pp. 263-268). St. Joseph, MI: ASAE.

Brown-Brandl, T. M., Eigenberg, R. A., Hahn, G. L., Nienaber, J. A., Mader, T. L., Spiers, D. E., \& Parkhurst, A. M. (2005). Analyses of thermoregulatory responses of feeder cattle exposed to simulated heat waves. International Journal of Biometeorology, 49, 285-296.

de Koning, K., van der Horst, Y., \& Meijering, A. (2002). Automatic milking experience and development in Europe. In First North
American Conference on Robotic Milking (pp. I1-I10). Wageningen: Wageningen Academic Publishers.

Eigenberg, R. A., Brown-Brandl, T. M., Nienaber J. A., \& HAHN, G. L. (2005). Dynamic response indicators of heat stress in shaded and non-shaded feedlot cattle: Pt. 2. Predictive relationships. Biosystems Engineering, 91, 111-118.

Eigenberg, R.A., Hahn, G. L., Nienaber, J. A., Brown-Brandl, T. M., $\&$ SPIERS, D. E. (2000). Development of a new respiration rate monitor for cattle. Transactions of the ASAE, 43, 723-728.

Eigenberg, R. A., Nienaber, J. A., \& Brown-Brandi, T. M. (2003, July). Development of livestock safety monitor for cattle. Paper presented at the ASAE Annual Meeting, Las Vegas.

Howell, P. J. L., \& PAICE, M. E. R. (1989). An adaptive datalogging system for animal power studies. Journal of Agricultural Engineering Research, 42, 111-121.

Mader, T. L., Dahlquist, J. M., Hahn, G. L., \& Gaughan, B. (1999). Shade and wind barrier effects on summertime feedlot cattle performance. Journal of Animal Science, 77, 2065-2072.

Pastell, M., Hautala, M., Poikalainen, V., Praaks, J., Veermäe, I., Kujala, M., \& AhoKas, J. (in press). Automatic observation of cow leg health using load sensors. Computers \& Electronics in Agriculture.

Rousing, T., Bonde, M., Badsberg, J. H., \& Sørensen, J. T. (2004). Stepping and kicking behaviour during milking in relation to response in human-animal interaction test and clinical health in loose housed dairy cows. Livestock Production Science, 88, 1-8.

Rushen, J., Boissy, A., Terlouw, E. M. C., \& De Pasillé, A. M. B. (1999). Opioid peptides and behavioral responses of dairy cows to social isolation in unfamiliar surroundings. Journal of Animal Science, 77, 2918-2924.

Spain, J. N., \& SpIERS, D. E. (1996). Effects of supplemental shade on thermoregulatory response of calves to heat challenge in a hutch environment. Journal of Dairy Science, 79, 639-646.

Spiers, D. E., Spain, J. N., Leonard, M. J., \& LuCy, M. C. (2001). Effect of cooling strategy on dairy cow performance during heat stress. In R. R. Stowell, R. Bucklin, \& R. W Bottcher (Eds.), Livestock Environment VI: Proceedings of the 6th International Symposium (ASAE Pub. 701P0201, pp. 45-55). St. Joseph, MI: ASAE.

WenZel, C., SchöNReiter-Fischer, S., \& UnShelm, J. (2003). Studies on step-kick behavior and stress of cows during milking in an automatic milking system. Livestock Production Science, 83, 237-246.

(Manuscript received September 30, 2005; revision accepted for publication February 28, 2006.) 